\title{
A pedagogia da alternância: inclusão social e humanização do homem do campo
}

\section{The pedagogy of alternation: social inclusion and humanization of the country man}

\author{
${ }^{1}$ Elizabeth Macedo Fagundes bethfagundes2007@yahoo.com.br \\ ${ }^{2}$ MariaLediana Bock
}

\begin{abstract}
RESUMO
O objetivo da pesquisa é problematizar a Pedagogia da Alternância voltada para a educação no campo, pois reconhecemos que a zona rural apresenta particularidades em relação as exigências da educação formal vivenciada pelas escolas da área urbana. A zona rural demanda uma formação educativa que contemple, em um só projeto pedagógico, a integralização de dois saberes: o teórico e o prático. Num processo de formação que colabore com a valorização desse segmento social e da modernização e desenvolvimento da área rural. Nesse sentido, iremos problematizar o regime de alternância com o objetivo de observar suas potencialidades e também suas limitações. O intuito é aprofundar os debates em torno do tema e contribuir, a partir das reflexões, com novos modos de se relacionar com a educação rural para que ela seja inclusiva e que minimize a defasagem das trajetórias escolares, não afugentando os alunos da participação de processos de ensino-aprendizagem positivos, diminuindo os índices de repetentes e de desistências.
\end{abstract}

Palavras-chave: Trajetórias escolares. Trabalho. Zona rural.

\section{RESUMEN}

El objetivo de la investigación es problematizar la Pedagogía de la Alternancia aplicada em la educación rural, pues reconocemos que el campo presenta particularidades com relación a las exigencias de la educación formal impartida em escuelas de la zona urbana. La formación educativa em la zona rural debe contemplar, en un único proyecto pedagógico, la integración de dos saberes: el teórico y el práctico, em um proceso de formación que colabore com la valorización de este segmento social y com la modernización y desarrollo de la zona rural. En este sentido, discutiremos el régimen de alternância com el objetivo de observar sus potencialidades y también sus limitaciones. La finalidad es profundizar em los debates sobre el tema y contribuir, a partir de las reflexiones, com nuevos modos de relacionar se com la educación rural para que sea inclusiva y reduzca la brecha entre las trayectorias escolares, sinahuyentar a los alumnos de la participación em el proceso de enseñanza y aprendizaje positivos, disminuyendo así los índices de recursantes y las deserciones.

Palabras-clave: Trayectorias escolares. Trabajo. Zona rural.

1 Faculdade Guairacá

2 Universidade Estadual do Centro Oeste - UNICENTRO 


\section{INTRODUÇÃO}

A Pedagogia da Alternância ainda é um assunto que precisa de mais atenção governamental. Apesar de existirem iniciativas de diferentes setores sociais para a articulação de parcerias voltadas para esse modelo educativo, ainda assim, os projetos em andamento deixam expostas as dificuldades e barreiras para se estabelecer um sistema educativo de alternância eficiente, de qualidade, que cumpra o objetivo principal dessa modalidade de ensino, que é, de modo coerente, unir, num projeto de formação integral e humanizadora, o saber teórico aliado ao saber prático a partir de uma perspectiva de ensino mais elástica, flexível as especificidades dos sujeitos e dos contextos nos quais estão inseridos. Nesse sentido, a pedagogia da alternância voltada para a população de zonas rurais é ainda mais significativo, principalmente se levarmos em consideração que esse segmento da sociedade necessita de uma formação educativa que contemple as particularidades do grupo, tanto no que refere-se a acessibilidade das escolas como ao incentivo de uma educação preparada para dar suporte ao desenvolvimento do homem do campo e a sua permanência na zona rural. Nesse sentido, o objetivo é problematizar o conceito de pedagogia da alternância e a prática da educação no campo para inferir acertos e erros desse modelo, com o propósito de contribuir com o debate do tema, chamando atenção para o potencial e os benefícios que a Pedagogia da Alternância, se explorada em toda sua potencialidade, pode trazer para a valorização do trabalhador rural e para a diminuição do êxodo rural. E, principalmente, pela necessidade de se colocar em prática novas propostas pedagógicas e organizacional que contribuam para o sucesso das trajetórias escolares.

\section{PEDAGOGIA DA ALTERNÂNCIA E A EDUCAÇÃO NO CAMPO: PROBLEMATIZAÇÕES}

A Pedagogia da Alternância tem um perspectiva pedagógica diferenciada dos modelos em funcionamento nas escolas de ensino tradicional. Sua particularidade reside na proposta educativa de articulação entre teoria e prática que objetiva englobara os conhecimentos convencionais às peculiaridades e necessidades dos indivíduos da zona rural. O surgimento da Pedagogia da Alternância no ano de 1935, na França, está ligada a insatisfação de um grupo de camponeses com a educação oferecida ao seus filhos, que defendiam a necessidade de práticas educativas que "atendesse às particularidades psicossociais dos adolescentes e que também propiciasse, além da profissionalização em atividades agrícolas, elementos para o desenvolvimento social e econômico da sua região" (TEIXEIRA; BERNARTT;TRINDADE, 2008, p. 229).Desse modo, além da adaptação dos conteúdos trabalhados em sala de aula, ainda prevê-se uma maior maleabilidade no calendário letivo e a ampliação das fronteiras físicas da escola, que estendem para ações de aprendizagem em outros espaços sociais, como: propriedades rurais, assentamentos, acampamentos, entre outras formas de movimento social nas quais a comunidade e os alunos estão vinculados. Portanto, de modo geral, a Pedagogia da Alternância tem o propósito de uma formação humanista que englobe, necessariamente, o ensino formal ao trabalho produtivo, valorizando e incentivando o crescimento do homem do campo. Sobre a Pedagogia da Alternância, Ribeiro (2006a) faz as seguintes considerações:

Neste tempo/lugar fariam um curso de agricultura por correspondência e, junto com este curso, receberiam uma formação geral, humana e cristã, orientada pelo padre. Assim nasce a Pedagogia da Alternância, onde se alternam tempos/lugares de aprendizado, sendo uma formação geral e técnica em regime de internato, em um centro de formação, e um trabalho prático na propriedade familiar e na comunidade. (Ribeiro, 2006a, p. 2)

Nesse sentido, afirmamos que a educação rural pública se impõem como um desafio para o Brasil. Os avanços que ocorreram ainda são localizados e necessitam de maior amplitude. São mazelas históricas que o Brasil ainda não conseguiu sanar, e que aprofunda a desigualdade social e a hierarquização de classes, com uma divisão desigual e injusta das riquezas da terra, além dos prejuízos humanos e sociais que a exclusão educacional 
fomenta, atrasando o desenvolvimento (no amplo sentido, que extrapola as relações apenas econômicas) do país. A educação fica fragilizada, os indivíduos privados de estímulos para desenvolver suas potencialidades e sensibilidades, e a pátria não se desenvolve. Quando falamos em educação rural, as falhas ficam ainda mais evidentes. Segundo o Censo ${ }^{3}$ Escolar do ano de 2015 foram as taxas de evasão escolar ainda são preocupantes, apresentando necessidade de novas estratégias para conter o abandono escolar e não agravar a distorção entre idade-série. A situação mais crítica com um índice de evasão e reprovação alarmantes, chegando ao percentual de 16,6\% de reprovação e 8,8\% de evasão, se concentra no primeiro ano de ensino médio, ou seja, esse cálculo representa o seguinte número de indivíduos: 530.928 e 281.456, respectivamente. Portanto, é inegável que precisamos achar respostas para os novos desafios impostos pela educação, buscando projetos e práticas que alavanquem positivamente as trajetórias escolares, num movimento de inclusão e democratização da educação ${ }^{4}$.

Ainda sobre o educação no campo, temos o agravante a falta de professores com preparo para desenvolver uma modalidade diferente de ensino, dispostos a trabalharem de modo consonante com a Pedagogia da Alternância, em processos de ensino voltados principalmente para a experiência cotidiana do homem do campo, valorizando a relação com a terra, o espaço, o mundo e o outro. No entanto, embora os conceitos teóricos que envolvem as práticas da Pedagogia da Alternância contemplarem uma abordagem educacional do ser em sua globalidade, em sua interação espaço/tempo, ensino/trabalho, ainda é preciso ressaltar que na prática, muitas dessas atividades, tem dificuldades em se concretizar de modo ideal, atingindo todos os objetivos que são propostos teoricamente. Assim, as ações não ocorrem de maneira homogênea e muitas são as vezes que diferentes situações limitam e até impedem a sua realização plena, conforma as concepções teóricas que fundamentam suas práticas.

Assim sendo, esse estudo reflete sobre os limites entre teoria e práxis da Pedagogia da Alternância na educação no campo, para observar como se dá as interações entre teoria e prática. No entanto, ainda é preciso manter-se crítico a práticas educativas de simples caráter tecnicista, nas quais as orientações pedagógicas são voltadas à formação de mão-de-obra barata e qualificada ao mercado. Assim, as experiência que envolve a Pedagogia da Alternância e a educação no campo pode ser tanto uma educação libertadora como uma educação que retroalimenta o sistema do capital e sua relação "servil” com o trabalho. Segundo, Ribeiro (2008) o desafio para os educadores-pesquisadores consiste em:

analisar as potencialidades e as limitações dessas experiências para a construção de um projeto democrático-popular de sociedade e de educação, buscando averiguar suas contribuições nas áreas de currículo, estágio, formação de professores, entre outras. Há necessidade de aprofundar o conhecimento sobre a Pedagogia da Alternância, também porque esta começa a ser adotada em alguns países como a França, a Suécia e o Canadá, como política pública de formação em tempos/espaços alternados de educação formal e de trabalho em empresas, numa forma de estágio orientado e remunerado. (RIBEIRO, 2008, p. s/p)

Desse modo, a argumentação que defende o uso capitalista da formação do trabalhador rural, justificando que o Estado teria menores gastos públicos com a formação dessa parcela da sociedade, pois grande parte dos envolvidos nesses projetos, na sua maioria, não são professores públicos, mas entidades religiosas, ONGs, sindicatos e associações comunitárias que assumem a administração das Casas Familiares Rurais (CFRs) e das Escolas Famílias Agrícolas (EFAs). Dessa forma, tais organizações não-governamentais eximem o Estado da maior parte da carga de responsabilidade pela formação de crianças, jovens e adultos do meio rural.

3 Para mais informações sobre os índices de evasão das escolas da rede pública, consultar o site do Instituto Nacional de Estudos e Pesquisas Educacionais Anísio Teixeira - INEP, no qual consta os arquivos de dados do último censo escolar, realizado no ano de 2015. Acessar: http:// portal.inep.gov.br/basica-censo

4 Para informações mais detalhadas consultar o site: http://www.qedu.org.br/brasil/taxas-rendimento 
Portanto, é preciso ter em mente que se os professores não tiverem a educação adequada, voltada para a perspectiva e os ideais da Pedagogia da Alternância, provavelmente, fracassaram na qualidade da formação oferecida a sociedade rural. Desse modo, é necessário que se mantenha em foco a relação de identidade entre os movimentos sociais, as lutas camponesas e os direitos a igualdade e cidadania que devem privilegiar as Diretrizes da Educação Básica nas Escolas do Campo. Segundo parecer da Câmara Nacional de Educação (CNE) e a Câmara de Educação Básica (CEB), homologada no ano de 2002:

\begin{abstract}
A educação do campo, tratada como educação rural na legislação brasileira, tem um significado que incorpora os espaços da floresta, da pecuária, das minas e da agricultura, mas os ultrapassa ao acolher em si os espaços pesqueiros, caiçaras, ribeirinhos e extrativistas. $\mathrm{O}$ campo, nesse sentido, mais do que um perímetro não urbano, é um campo de possibilidades que dinamizam a ligação dos seres humanos com a própria produção das condições da existência social e com as realizações da sociedade humana (BRASIL-BRASÍLIA, 2002, s/p)
\end{abstract}

A Pedagogia da Alternância aplicada ao ensino-aprendizado do homem do campo tem um expressivo potencial de desenvolvimento, podendo ser ferramenta para a libertação e autonomia do homem do campo, pois, por meio dela, podemos alcançar situações mais justas de igualdade de oportunidades, transformando socialmente a realidade, possibilitando novas chances de inclusão social aos indivíduos que vivem a expropriação da terra, dos meios de produção e, portanto, de sobrevivência.

Há quase meio século que projetos envolvendo a perspectiva da Pedagogia da Alternância estão sendo desenvolvidos no território brasileiro. O paraná foi o primeiro estado que implantou métodos pedagógicos relacionados a área rural, no entanto, ainda não é necessário que ocorra uma maior abrangência de projetos de formação e inclusão social dos indivíduos da zona rural, pois é inegável o direito que também essa parcela da população tem de pertencer a um sistema de educação diferenciado, que esteja preparado para a valorização o homem do campo e para o desenvolvimento de sua cidadania. Para a Secretaria de Educação Continuada, Alfabetização e Diversidade (SECAD):

A Constituição de 1988 é um marco para a educação brasileira porque motivou uma ampla movimentação da sociedade em torno da garantia dos direitos sociais e políticos, dentre eles o acesso de todos os brasileiros à educação escolar como uma premissa básica da democracia. Ao afirmar que "o acesso ao ensino obrigatório e gratuito é direito público subjetivo” (Art. 208), ergueu os pilares jurídicos sobre os quais viria a ser edificada uma legislação educacional capaz de sustentar o cumprimento desse direito pelo Estado brasileiro. No bojo desse entendimento, a educação escolar do campo passa a ser abordada como segmento específico, prenhe de implicações sociais e pedagógicas próprias. (SECAD, 2007, p. 16)

Nesse sentido, fica evidente a importância de um trabalho pedagógico direcionado as peculiaridades da zona rural e dos seus moradores, pois é necessário que as políticas governamentais se atentem para os direitos à cidadania e à educação que sociedade rural precisa, voltado para a possibilidade de se ter uma educação de qualidade sem para isso precisar deixar o campo. E, por isso, a ampliação de debates que envolvam o tema: educação rural, deve ser visto como prioridade, tanto pelo setor público como pelo setor privado. Só assim alcançarem, a partir da educação, a inclusão social e a equidade de direitos, numa perspectiva que contemple a formação humanística dos sujeitos que vivem e trabalham no campo. 


\section{3 “BRASIL, PÁTRIA EDUCADORA”5 : SERÁ?}

Como já diz com maestria João Cabral de Melo Neto em seu poema “Morte e vida Severina”, ao referenciar a desigualdade social e a concentração de terras na mãos de poucos, nos versos: "Esta cova em que estás, com palmos medida (...) É de bom tamanho, nem largo nem fundo, é a parte que te cabe, deste latifúndio. Não é cova grande, é cova medida, é a terra que querias ver dividida” (MELO NETO, 2003, p. 183), evidenciando que a má distribuição de terras no território brasileiro é um fato histórico e ainda hoje é possível observar como a concentração de riquezas entre os indivíduos é dispare e cria um fosso para o desenvolvimento justo e pleno da cidadania e da qualidade de vida. Por isso, problematizar os programas educativos e salientar a importância de projetos pedagógicos que incluam ações práticas de luta pela democratização do ensino, num combate ao ausentismo e a repetência de ano, é essencial para a motivação e o sucesso nas trajetórias escolares. E quando falamos em educação no espaço rural fica ainda mais evidente as fragilidades do modelo educativo tradicional, que segue uma padronização das trajetórias escolares relacionado tempo e conteúdo. Os alunos precisam cumprir determinadas metas, numa concepção teórica que pressupõe a ideia de igualdade e homogeneização do ensino, num movimento de padronização de processos educacionais que desconsideram, em maioria, as especificidades dos espaços sociais, das práticas culturais e econômicas e dos indivíduos (e seus interesses). Essa situação, em contrapartida, tem gerado também alguns resultados negativos, como falta de resposta frente a heterogeneidade, repetência e um índice considerável de interrupção dos estudos entre o nível primário e secundário.

Em estudos sobre as trajetórias escolares na Argentina, a autora Terigi (2007) reflete sobre a massificação das políticas educativas, salientando que durante décadas esse formato pedagógico incorporou especificamente o ensino fundamental, mas que atualmente tem ocorrido também essa massificação na Educação Infantil e no Ensino Superior. Nesse sentido, a concepção educacional em atuação considera o tempo como uma condição do currículo, o que por sua vez, segundo a pesquisadora, sustenta a ideia de cronologia de aprendizagens em curso.

El tercer rasgo es la anualización de los grados de instrucción, que estabelece el tiempo previsto para el cumplimiento de esos grados. Debido a la anualización, el tiempo se convierte en una condición para el curriculum; al cabo de certo tiempo, el curriculum estabilizado contribuye a naturalizar los tempos así escolarizados. Una concepción monocrónica del tiempo escolar, la idea de una única cronología de aprendizajes en curso, aparece como respuesta institucional del sistema educativo al propósito de la escolarización masiva. (TERIGI, 2007, p. 3)

Levando em consideração o exposto acima, as trajetórias escolares devem ser analisadas levando em consideração sua faceta teórica e prática. Para isso, retomando as reflexões de Terigi (2007), assinalamos que em nível teórico as trajetórias são delimitadas a partir da progressão linear, da periodização, organização de sistemas por níveis, gradualidade do currículo e anulação dos graus de instrução. Enquanto no nível prático, as trajetórias reais, são marcados por situações recorrentes de defasagem de estudantes, repetência e vulnerabilidade. Sobre esse contexto, a autora discorre:

una serie de câmbios em las culturas juveniles y em las expectativas de inclusión educativa desafían desde hace tempo las funciones y la organización tradicional de la escuela secundaria. Em su origen selectiva y conun currículo comprehensivo y academicista, diferenciada tempranamenteen modalidades profesionales y propedéuticas, la escuela secundaria debe enfrentar hoy nuevos tiempos y nuevos públicos. La llegada de nuevos sectores sociales ha contribuido a desestabilizar los acuerdos previos sobre este nivel educativo, y enfrenta a los gobiernos y a las escuelas com los límites de las tradiciones pedagógicas y de la organización institucional (TERIGI, 2007, p. 1)

Ainda em referência aos estudos de Terigi (2007) citamos a estreita relação entre os altos índices de repetência e o modelo educacional que alia "gradualidad/anualización”, num sistema que não desvincula com facilidade as consequências entre o modelo educativo cronológico e linear e as falhas da organização escolar de concepção "monocromática do tempo". Segundo a autora:

5 O título faz referência ao lema do governo da presidente do Brasil Dilma Rousseff. Em discurso presidencial foi citado que os investimentos na área de educação seriam prioridade do seu mandato. 
La segunda observación que puede ayudarle es las iguiente: numerosos países no incluyen la repitencia entre las trayectorias teóricas de sus estudiantes secundarios, porque no asocian gradualidad y anualización. La regla es lapromoción conjunta de los alunos pertenecientes a um mismo grupo, y la diferenciación de los recorridos de aprendizaje dentro de los grupos, em el marco de sólidos cuestionamientos a la eficacia de la repetición. Estas prácticas, que em nuestro país serían catalogadas rápidamente de “disminuciónen las exigencias”, las aplican países de ressonante éxito educativo em las mediciones internacionales, como Finlandia, Noruega y Australia (Briseid y Caillods, 2003). (TERIGI, 2007, p. 4)

Desse modo, com base no diálogo entre as experiências na Argentina e a realidade do Brasil, estabelecemos paralelos de reflexão que buscam ampliar as possibilidades de debate sobre os processos educativos de ambos os países. O que observamos é que nos dois casos encontramos a necessidade de encontrar modos de acompanhar e orientar os alunos e os familiares, contribuindo a partir de ações educativas produtivas com a integração entre aluno, escola, trabalho e conhecimento. Assim, atentarmos para a exigência dos tempos atuais que é a de dar respostas a heterogeneidade que compõe o quadro de alunos e situações sociais específicas.

\begin{abstract}
A hora bien, el desafio del ausentismo presenta diferencias según cuál esse na las razones que subyacen a él. Em efecto, según surge de diversos estudios (Jacinto y Terigi, 2007), no hayun único motivo de ausentismo: se falta a las primeras horas de classe del turno nocturno porque se superponen con el horario de trabajo; se está ausente durante un período prolongado como consecuencia de la maternidad, o de trabajos ocasionales; se abandona temporalmente y luego se retoma la escolaridad, em el marco de una experiencia escolar de baja intensidad signada por inasistencias esporádicas pero numerosas y por una relación tensa com la escuela. Desde el punto de vista de las respuestas pedagógicas que se requieren, conocer estas diferencias y comprender sus consecuencias resulta estratégico para generar propuestas que puedan resolver mejorla difícil ecuación entre el menor tiempo de asistencia e instrucción, y el logro de los aprendizajes básicos del currículo. (TERIGI, 2007, p. 17)
\end{abstract}

Conforme defende Terigi (2007), é preciso que as políticas educativas garantam o alcance dos objetivos de aprendizagem, o que por sua vez implica em colocar em prática novos recursos pedagógicos e institucionais, num incentivo para que os jovens progridam em sua trajetória escolar. Para isso, é importante que ocorra a elaboração de programas de estudo específicos com metas de aprendizagem desvinculadas do ciclo letivo e ano escolar. Só dessa forma, será possível evidenciar o desajuste da "anualización”.

No se trata de "normalizar las trayectorias", sino de ofrecer una amplia gama de trayectorias educativas diversas y flexibles. Como hemos sostenido en diversas oportunidades, se trata de diversificar los formatos en que tiene lugar la experiencia escolar, sin renunciar a los aprendizajes a que todos tienen derecho, desafiando los destinos que se presentan como inevitables. (TERIGI, 2007, p. 18)

Portanto, tal qual sugere a meta do governo brasileiro de manter a área da educação como prioridade de investimentos, é preciso que também se atente para o desenvolvimento de políticas educativas funcionais, que não engessem o sistema educativo numa massificação alienante que não cumpre o objetivo maior que é o desenvolvimento integral do indivíduo, com o intuito de oferecer ferramentas pedagógicas de incentivo a autonomia e libertação, tal qual sugere o educador Paulo Freire (1978), ao referir-se a educação como "um ato de amor, por isso, um ato de coragem. Não pode temer o debate. A análise da realidade. Não pode fugir à discussão criadora, sob pena de ser uma farsa” (p. 98). Por isso, educar não é dar palavras de ordem, nem reproduzir sistemas de opressão e dominação de um indivíduo sobre o outro ou de um grupo sobre o outro. Ou seja, segundo Freire (1978) trata-se da exploração do "homem simples esmagado, diminuído e acomodado, convertido em espectador, dirigido pelo poder dos mitos que forças sociais poderosas criam para ele” (p. 53), o que significa que a educação para essa parcela da população não é um ato de libertação, mas um aprisionamento. 


\section{EDUCAÇÃO NO CAMPO: A NECESSIDADE DE UM PROJETO PEDAGÓGICO DE INCLUSÃO SOCIAL}

Briscioli (2015) em estudo sobre a relação entre as condições de escolarização e o processo de construção das trajetórias escolares, com foco nas "escuelas de reingreso" da cidade de Buenos Aires, diagnosticou que ainda existe um fosso entre a passagem dos estudantes do nível primário ao nível secundário de estudos, ou seja, não ocorrem ações educativas de assistência, que contribuam com a diminuição do índice de desistências. Nesse sentido, a autora reflete sobre a necessidade de aplicação de projetos que garantam a inclusão dos alunos, garantindo o acesso e a democratização do ensino de qualidade, para frear o "empeoramiento" que é evidente na passagem de um nível escolar para o outro. A autora ainda ressalta que a matriz do Nível Secundário adquiriu, de modo geral, uma caráter negativo, de expulsão que é "manifiesto em la obstaculización de los tránsitos por la escolaridade obligatoria” (BRISCIOLI, 2015, p. 11).No Brasil, os dados estatísticos do último censo escolar (já citado e referenciado anteriormente) demonstram problemas semelhantes, com índices de desistência maiores na passagem do Ensino Fundamental para o Ensino Médio, o que reforça a condição de assistidos de grande parcela da população de ambos os países. Assim, podemos inferir que nos dois contextos:

La perspectiva de las trayectorias escolares muestra que las dificultades em los trânsitos por el sistema escolar se producen por una sumatoria de situaciones. Entre ellas, postulamos centralmente que, las condiciones de escolarización estándar constituyen nun obstáculo para la progresión por el Nivel Secundario. ((BRISCIOLI, 2015, p. 23)

Como cita Briscioli (2015) as instituições escolares que funcionam a partir da perspectiva da "anualización” apresentam índices maiores de abandono dos estudos principalmente na passagem do nível primária para o secundário, o que agrava a desigualdade social. Os alunos que não se enquadram nessa dinâmica e apresentam resultados de desempenho abaixo da média são estigmatizados em sala de aula,

en todos estos casos, las instituciones escolares actuaron degradando a los alumnos, bajo la amenaza o la acción concreta de ubicarlos em un grado inferior al que debían haber cursado; o cambiándolos de un turno a otro, que em el imaginario (escolar, pedagógico y social) está destinado a los alumnos de “peor reputación. (BRISCIOLI, 2015, p. 14)

Por isso, é importante que novas propostas pedagógicas e organizacional sejam pensadas e colocadas em prática, pois a educação deve ser objeto prioritário de qualquer governo que vise o real desenvolvimento do país. O acesso à educação faz parte do direito à cidadania e a integração social e, nesse sentido, é imprescindível que se ofereça aos estudantes saberes relevantes, que levem em considerações as especificidades dos agentes envolvidos nos processos educativos. Só assim será possível estabelecer a ponte entre informação/conhecimento, teoria/prática.

Portanto, também estabelecendo ponte entre as reflexões desse estudo e as ideias de Briscioli (2015), reforçamos a importância da criação de alternativas para a metodologia pedagógica das escolas tradicionais, na tentativa de resolução dos impasses criados para o alcance de trajetórias escolares bem sucedidas. O direito à educação de qualidade é princípio humanizador, a partir dele é possível garantir índices satisfatórios de desenvolvimento social e de melhorias, concomitantemente, em outras áreas. Segundo Briscioli (2015) é preciso mudar, urgentemente, "las condiciones de escolarización de la escuela secundaria estándar. Si seguimos obstinados em hacer lo mismo, perpetuamos la exclusión. En cambio, si ensayáramos innovaciones podríamos tender a un sistema educativo más justo. (BRISCIOLI, 2015, p. 27)

Voltando as discussões que envolvem a educação do homem do campo, ressaltamos que ao entrar nessa área os problemas de desistência e repetição, geralmente, se agravam. E, por isso, a Pedagogia da Alternância surge como uma nova possibilidade de ser pensar a relação entre a educação e o meio social. Para Jacinto (2010) a situação ainda é agravada pela falta de condições da maior parte da população de investir em capitais socioeducativos, 
no qual seria possível complementar a formação escolar, o que para a autora reflete, "una marcada segmentación intra-generacional que se profundiza a causa de las dispares oportunidades educativas” (JACINTO, 2010, p. 181).

A luta empreendida deve ser, portanto, pela inclusão social e a democratização do ensino a partir de pedagogias alternativas à perspectiva tradicional dominante, que impõem limitações a partir de práticas de homogeneização do conhecimento. Os sujeitos sociais envolvidos da dinâmica da aprendizagem devem ser observados também em suas especificidades. O contexto social da zona rural é marcado por práticas culturais que o diferem do espaço urbano das cidades e isso é importante ser avaliado quando se propõe novas abordagens educativas. A Pedagogia da Alternância, nesses casos, pode ser incorporada como modelo para o desenvolvimento de projetos socioeducativos integrados ao meio prático de vivência dos alunos. A integração entre escola e família, nesses casos, torna-se ainda mais importante, pois é a partir do apoio entre ambos que se potencializa os resultados positivos na formação do aluno e na transformação do meio em que ele vive.

A educação voltada para o homem do campo deve preservar a cultura rural e por isso é necessário a adequação do conteúdo à realidade dos educandos, além de ser imprescindível a capacitação docente, pois é preciso trabalhar com uma metodologia adequada. Outra aspecto importante desse processo de inclusão social é o acesso dos estudantes a transportes públicos eficientes, que garantam o deslocamento seguro até as escolas além, claro, da possibilidade de uma calendário letivo mais flexível, que leve em consideração os períodos de safra e colheitas. Quando todos essas questões são resolvidas, as chances de sucesso nas trajetórias escolares de estudantes do meio rural aumentam expressivamente.

É importante que os estudantes da área rural estejam incorporados a processos de ensino que estimulem as relações entre o conhecimento teórico e a prática das atividades rurais, pois faz-se necessário pensar o campo como espaço dinâmico e de interação com o todo social, fortalecendo a relevância de lutas por políticas públicas inclusivas. Assim, incentivar a diversificação das atividades desenvolvidas nas propriedades camponesas faz parte do processo de valorização dos trabalhadores rurais e da agricultura. Principalmente, em países em desenvolvimento e que ainda apresentam índices consideráveis de distorção entre idade e série.

\section{CONCLUSÃO}

Diante das reflexões desenvolvidas nessa pesquisa, destacamos que a concepção da Pedagogia da Alternância supõe as práticas educativas como processos dinâmicos e complexos, que necessitam estar concatenadas com os diferentes espaços e cultura (s) do homem do campo. Assim a relação tempo/espaço precisa ser reformulada no trabalho pedagógico, para garantir a integração entre teoria e prática. Por isso, é importante desfazer ideias do senso comum que compreendem essa modalidade educativa superficialmente como apenas períodos alternados entre casa e escola. E, nesse sentido, a formação adequada dos professores é fundamental para que ocorram as intervenções necessárias entre o saber e a realidade, num sistema de ensino e aprendizagem que englobe tanto conteúdos humanísticos como técnicos, tal como assevera Queiroz (2004) ao dizer que: “o grande desafio para a escola da alternância é articular essas relações com o saber na integração realidade da escola e realidade do trabalho. Pois não se trata apenas de articular os dois espaços, dois lugares diferentes. Mas é necessário colocar em coerência duas relações com o saber num projeto de formação” (p. 103). O que por sua vez reforça a afirmação do autor sobre a necessidade de uma pedagogia do saber partilhado, que não ignore as contradições e particularidades dos sujeitos envolvidos.

Portanto, para alcançar os objetivos da Pedagogia da Alternância aplicada ao homem do campo é preciso que ocorra um movimento de integração e participação coletiva, na qual os diferentes sujeitos sociais (entre eles citamos: pais, professores, alunos, movimentos sociais, associações locais) estejam em consonância com os ideais desse modelo de ensino. A proposta pedagógica da alternância é, portanto, uma alternativa viável ao ensino rural, pois integra de modo eficiente as aspirações dos educandos contribuindo para a democratização do ensino. Ela mantém o interesse dos mesmos ao explorar, nos processos de aprendizagem, a interface com o contexto social, freando os índices de desistência e reprovação e incentivando o desenvolvimento da esfera sócio profissional, o que por sua vez reflete em trajetórias escolares de sucesso. 


\section{REFERÊNCIAS}

ARroyO, M. G.; CALDART, R.; MOLINA, M. C. Por uma educação do campo. Petrópolis: Vozes, 2004.

BRASIL - BRASÍLIA. Superior Tribunal Federal. Diretrizes Operacionais para a Educação Básica nas Escolas do Campo, n 23001.000329/2001-55. Câmara de Educação Básica do Conselho Nacional de Educação. Relator: Edla de Araújo Lira Soares. Brasília, DF de 2002. Brasília, 12 mar. 2002. Disponível em: <http://portal. mec.gov.br/index.php?option=com_docman\&view=download\&alias=6803-pceb036-01\&Itemid=30192>. Acesso em: 05 out. 2016.

BRISCIOLI, Bárbara. La incidencia de las condiciones de escolarizacióndel Nível Secundário em laconstrucción de lastrayectorias escolares. Revista Perfiles Educativos. Vol XXXVIII, n. 154, 2016. IISUE-UNAM. Disponível em: http://132.248.192.201/seccion/perfiles/2016/n154a2016/mx.peredu.2016.n154.p134-153.pdf> . Acesso em: 8 de out. 2016.

DAMASCENO, M. N. Estudos sobre educação rural no Brasil: estado da arte e perspectivas. Educação e Pesquisa. São Paulo: FAE/USP, v. 30. n. 1., p. 51-72, jan./abr., 2004.

DUARTE, V. Escolas públicas no campo. Francisco Beltrão: Grafit, 2003.

FETAG/RS. Pedagogia da Alternância: uma forma diferente de capacitar jovens rurais: uma educação rural diferenciada. Revista Educação Rural. Porto Alegre. n. 2. p. 13-15; p. 25-27, set. 2006.

FREIRE, P. Educação como prática da liberdade. 8 ed. Rio de Janeiro: Paz e Terra, 1978.

JACINTO, Claúdia. La construcción social de lastrayectoriaslaborales de jóvenes: políticas instituciones, dispositivos y subjetividades. Compilação: Claudia Jacinto. Buenos Aires:Teseo; IOES,2010.

LEITE, S. C. Escola rural: urbanização e políticas educacionais. São Paulo: Cortez, 1999.

PESSOTTI, A. L. Escola da Família Agrícola: uma alternativa para o ensino rural. Rio de Janeiro.

QUEIROZ, João Batista P. de. Construção das Escolas Famílias Agrícolas no Brasil: Ensino Médio e Educação Profissional. Brasília, Departamento de Sociologia, 2004. 210p. Tese de Doutorado.

RIBEIRO, Marlene. Pedagogia da alternância na educação rural/do campo: projetos em disputa. Educ. Pesqui., [s.l.], v. 34, n. 1, p.1-14, abr. 2008. FapUNIFESP (SciELO). http://dx.doi.org/10.1590/s1517-97022008000100003.

Trabalho e educação na formação de agricultores: a pedagogia da alternância. In: ANPED-Sul. 6. 2006. Santa Maria: Anais. (CD-Rom). Santa Maria: UFSM, 2006a. 10 p.

SECAD: SECRETARIA DE EDUCAÇÃO CONTINUADA, ALFABETIZAÇÃO E DIVERSIDADE. Educação do Campo: diferenças mudando paradigmas. Brasília - DF - março de 2007. 81 p.

TEIXEIRA, Edival Sebastião; BERNARTT, Maria de Lourdes; TRINDADE, Glademir Alves (Org.). Estudos sobre Pedagogia da Alternância no Brasil: revisão de literatura e perspectivas para a pesquisa. Educação e Pesquisa, São Paulo, v. 34, n. 2, p.227-242, maio 2008. Disponível em: <http://www.scielo.br/pdf/ep/v34n2/02. pdf>. Acesso em: 03 out. 2016.

TERIGI, Flávia. Los desafíos que planteanlastrayectorias escolares. III Foro Latinoamericano de Educación: Jóvenes y Docentes. La Escuela Secundaria En El Mundo de Hoy X: III Foro Latinoamericano de Educación: jóvenes y docentes. La escuela secundaria enel mundo de hoy. Buenos Aires, p.1-20, 2007.

MELO NETO, J. C. Morte e vida severina. In: Obra Completa. Rio de Janeiro: Nova Aguilar, 2003. 